\title{
Novel pyrrolo- I,5-benzoxazepine compounds display significant activity against resistant chronic myeloid leukaemia cells in vitro, in ex vivo patient samples and in vivo
}

\section{SA Bright ${ }^{*, 1}$, AM McElligott ${ }^{2}$, JW O'Connell', L O'Connor², P Carroll ${ }^{3}$, G Campiani ${ }^{4}$, MW Deininger ${ }^{5}$, E Conneally ${ }^{3}, M_{\text {Lawler }}^{2}$, DC Williams', DM Zisterer'}

'School of Biochemistry and Immunology, Trinity College, Dublin 2, Ireland; ${ }^{2}$ Institute of Molecular Medicine, St. James's Hospital, Trinity College, Dublin, Ireland; ${ }^{3}$ Cancer Clinical Trials Office, St. James's Hospital, Dublin, Ireland; ${ }^{4}$ European Research Centre for Drug Discovery and Development,

Universita'degli Studi di Siena, Siena, Italy; ${ }^{5}$ Division of Hematology and Medical Oncology, Oregon Health and Science University, Portland, OR, USA

BACKGROUND: Imatinib is a direct and potent inhibitor of the constitutively active tyrosine kinase, breakpoint cluster region-Abelson (Bcr-Abl), which is central to the pathogenesis of chronic myeloid leukaemia (CML) patients. As such, imatinib has become the frontline treatment for CML patients. However, the recent emergence of imatinib resistance, commonly associated with point mutations within the kinase domain, has led to the search for alternative drug treatments and combination therapies for CML.

METHODS: In this report, we analyse the effects of representative members of the novel pro-apoptotic microtubule depolymerising pyrrolo- I,5-benzoxazepines or PBOX compounds on chemotherapy-refractory CML cells using a series of Bcr-Abl mutant cell lines, clinical ex vivo patient samples and an in vivo mouse model.

RESULTS: The PBOX compounds potently reduce cell viability in cells expressing the E225K and H396P mutants as well as the highly resistant T3 51 mutant. The PBOX compounds also induce apoptosis in primary CML samples including those resistant to imatinib. We also show for the first time, the in vivo efficacy of the pro-apoptotic PBOX compound, PBOX-6, in a CML mouse model of the T3।5I Bcr-Abl mutant.

CONCLUSION: Results from this study highlight the potential of these novel series of PBOX compounds as an effective therapy against $\mathrm{CML}$.

British Journal of Cancer (2010) I 02, I474- |482. doi:I0.1038/sj.bjc.6605670 www.bjcancer.com

Published online 20 April 2010

(c) 2010 Cancer Research UK

Keywords: PBOX; CML; T3I5l; Bcr-Abl; apoptosis

Chronic myeloid leukaemia (CML) is caused by breakpoint cluster region-Abelson (Bcr-Abl), a constitutively active tyrosine kinase that is the result of the reciprocal translocation between chromosome 9 and 22, $t(9 ; 22)$, cytogenetically visible as the Philadelphia chromosome (Deininger et al, 2000). The disease is thought to originate from the transformation of a haematological stem cell. Bcr-Abl-positive cells are resistant to apoptosis due to the continuous activation of signalling pathways downstream of Bcr-Abl, including the signal transducer and activator transcription and phosphatidyl inositol-3 kinase pathways. The majority of CML patients are diagnosed in the chronic phase that is easily managed with the novel kinase inhibitor, imatinib (imatinib mesylate; STI571; Gleevec), which directly targets the oncogenic Bcr-Abl protein (Deininger et al, 2005). However, some patients acquire resistance to imatinib and progress to a more aggressive phase of disease termed the accelerated phase and eventually the blastic phase, which resembles an acute leukaemia that is largely resistant to imatinib and rapidly fatal (Deininger and Druker, 2003). Even in patients reaching a complete cytogenetic response,

*Correspondence: Dr SA Bright; E-mail: brights@tcd.ie Revised 26 February 20 I0; accepted 24 March 20 I0; published online 20 April 2010 residual disease remains detectable by PCR techniques suggesting a continued threat of relapse (O'Hare et al, 2008).

There are many different mechanisms through which patients become resistant to imatinib, including an increase in the levels of Bcr-Abl protein expression levels through amplification of the $\mathrm{Bcr}-\mathrm{Abl}$ gene, an efflux of imatinib through multi-drug resistant (MDR) proteins such as P-glycoprotein (P-gp) (Mahon et al, 2000) and activation of alternative signalling pathways downstream of or independent to Bcr-Abl (Capdeville et al, 2002). Progression of the disease can also be associated with additional mutations in oncogenes such as p53, Ras and retinoblastoma gene. However, the major mechanism of imatinib resistance is due to mutations at critical points in the Bcr-Abl gene. These Bcr-Abl mutations can occur in several functionally distinct regions within the kinase domain and confer varying degrees of insensitivity to imatinib. More than 60 different amino-acid substitutions have been found to date and many of these are mutated at more than one alternative residue (Apperley, 2007a, b). Mutations fall into two groups, those that alter amino acids that directly contact imatinib and those that prevent $\mathrm{Bcr}-\mathrm{Abl}$ from achieving the inactive conformational state required for imatinib binding. Of the mutations that result from amino-acid substitutions, the T315I and E255K mutations are among the most prevalent (Hughes et al, 2006). Crucially the T315I mutation is also associated with the highest degree of imatinib 
resistance, it prevents the formation of a critical hydrogen bond between imatinib and Bcr-Abl and changes the conformation of $\mathrm{Bcr}-\mathrm{Abl}$ to prevent imatinib binding.

These mutations raise the possibility that additional drugs that target CML cells through alternative mechanisms to Bcr-Abl have the potential to be successful in treating imatinib-resistant CML patients (Druker et al, 2001). As a result, a number of studies have been conducted with imatinib in combination with other anticancer therapeutics including farnesyltransferase inhibitors such as SCH66336 (lonafarnib) (Peters et al, 2001; Nakajima et al, 2003; Borthakur et al, 2006), mitogen-activated protein kinase pathway inhibitors PD184352, PD98059 and U0126 (Yu et al, 2002; Nguyen et al, 2006) and histone deacetylase inhibitors MS-275 and SAHA (suberoylanilide hydroxamic acid) among others (Kelly et al, 2003; Yu et al, 2003; Fiskus et al, 2006a) with varying degrees of success in in vitro and in vivo animal models. Nilotinib in combination with LBH589 also produced synergistic results (Fiskus et al, 2006b).

Another approach to overcome imatinib resistance has led to the development of novel second-generation Bcr-Abl tyrosine kinase inhibitors. Of these, dasatinib, an orally active, small molecule that inhibits Bcr-Abl, along with multiple other kinases including the SRC family kinases (Guilhot et al, 2007) and nilotinib (Tasigna; Novartis Pharmaceuticals, Basel, Switzerland), a phenyl aminopyrimidine analogue of imatinib, have recently been approved by the FDA for treatment of imatinib-resistant CML patients (McFarland and Wetzstein, 2009). Although these second-generation tyrosine kinase inhibitors are effective against many Bcr-Abl mutants, they are completely ineffective against the T315I mutants. Although third-line tyrosine kinase inhibitors with activity against T315I mutants are in clinical trials, it is likely that BcrAbl-independent resistance will arise in advanced CML, suggesting that agents that target CML cells through alternative mechanisms to $\mathrm{Bcr}-\mathrm{Abl}$ have the potential to be successful in treating imatinibresistant CML patients (Quintás-Cardama and Cortes, 2008b).

Recently, some members of a novel set of compounds, the pyrrolo-1,5-benzoxazepine (PBOX) compounds, have been shown to induce apoptosis in a wide range of solid tumours and haematological malignancies (Zisterer et al, 2000). Tubulin has been identified as the molecular target of these compounds that induce apoptosis in CML cells by bypassing Bcr-Abl (Mc Gee et al, 2001). The PBOX compounds have also shown efficacy in ex vivo chronic lymphocytic leukaemia (CLL) samples (McElligott et al, 2009) and in an in vivo mouse mammary carcinoma model (Greene et al, 2005). Furthermore, we have also shown that PBOX-6 in combination with imatinib enhances apoptosis in imatinib-resistant CML cell lines that overexpress the Bcr-Abl protein (Greene et al, 2007). It was therefore of interest to determine if the PBOX compounds could similarly induce/enhance apoptosis in CML cells that contain the highly resistant T315I mutation both in vitro and in vivo.

Using a series of Bcr-Abl mutant cell lines (O'Hare et al, 2008), we showed the ability of PBOX-6 and PBOX-15 to reduce viability in cells that contain the imatinib-resistant mutations E225K, $\mathrm{H} 396 \mathrm{P}$ and T315I in vitro. The PBOX compounds also induced apoptosis in clinical ex vivo CML patient samples including those resistant to imatinib whereas PBOX-6 reduced tumour load in a CML mouse model containing the T315I Bcr-Abl mutation. We conclude that the pro-apoptotic PBOX compounds have potential as novel therapeutics in the treatment of CML patients, including those harbouring the notorious T315I mutation.

\section{DESIGN AND METHODS}

\section{Cell culture}

The murine pro- $\mathrm{B}$ cell lines, Baf $/ 3$ cells, transfected with either the native or mutated versions of Bcr-Abl, were previously described (O'Hare et al, 2008). Baf/3 cell lines were grown in RPMI-1640 (GlutaMAX) medium supplemented with $10 \%$ (v/v) fetal bovine serum (FBS) and $50 \mu \mathrm{g} \mathrm{ml}^{-1}$ penicillin/streptomycin. Parental $\mathrm{Baf} / 3$ cells also required $10 \mathrm{ng} \mathrm{ml}^{-1} \mathrm{IL}-3$. Cells were grown in a humidified environment maintained at $95 \% \mathrm{O}_{2}$ and $5 \% \mathrm{CO}_{2}$ and passaged at least twice weekly. Cells were seeded at a density of $2 \times 10^{5}$ cells per ml.

\section{Reagents}

RPMI-1640 medium was obtained from Biosciences (Dublin, Ireland) and FBS from Invitrogen (Paisley, UK). The enhanced chemiluminescence reagents were supplied by Amersham Biosciences (Buckinghamshire, UK). The BCA reagents were purchased from Pierce (Rockford, IL, USA) and polyvinylidene difluoride membranes were sourced from Millipore (Cork, Ireland). Actin and Bcr-Abl antibodies were obtained from Calbiochem (Nottingham, UK) whereas the CD45 antibody was from BD Biosciences (Oxford, UK). Annexin V was obtained from IQ Products (Groningen, the Netherlands), Lymphoprep from Axis-Shield (Kimbolton, Cambridgeshire, UK) whereas the binding buffer and AlamarBlue dye were purchased from Biosource (London, UK). Imatinib was provided by Novartis Pharmaceuticals. All other reagents were purchased from Sigma (Tallaght, Dublin, Ireland).

\section{AlamarBlue viability assay}

$\mathrm{Baf} / 3$ cells expressing native or mutant $\mathrm{Bcr}-\mathrm{Abl}$ were seeded in $200 \mu \mathrm{l}$ medium in a 96-well plate. Cells were treated and incubated as required. AlamarBlue $(20 \mu \mathrm{l})$ was added to each well and incubated at $37^{\circ} \mathrm{C}$ in the dark for $3 \mathrm{~h}$. Plates were then read on a fluorescent plate reader (SpectraMax Gemini; Molecular Devices, Wokingham, Berkshire, UK) with excitation and emission wavelengths of 544 and $590 \mathrm{~nm}$, respectively. Experiments were performed in triplicate. A sample containing only reagent and medium was used as a blank. Vehicle samples were set as $100 \%$ viability from which any decrease in viability was calculated.

\section{Flow cytometry}

Baf $/ 3$ cells expressing native or mutant Bcr-Abl were seeded in 12 -well plates and treated with the designated compound/s or corresponding vehicle. After the required treatment time samples were centrifuged at $500 \mathrm{~g}$ for $5 \mathrm{~min}$. Cells were then resuspended in $100 \mu \mathrm{l}$ ice-cold phosphate-buffered saline (PBS) and ice-cold $70 \%(\mathrm{v} / \mathrm{v})$ ethanol $(1 \mathrm{ml})$ and stored overnight at $4^{\circ} \mathrm{C}$. Cells were subsequently pelleted at $800 \mathrm{~g}$ for $10 \mathrm{~min}$ and resuspended in $200 \mu \mathrm{l}$ PBS. RNase A $\left(10 \mu \mathrm{g} \mathrm{ml}^{-1}\right)$ and propidium iodide $\left(100 \mu \mathrm{g} \mathrm{ml}^{-1}\right)$ were then added to each sample and incubated for $30 \mathrm{~min}$ at $37^{\circ} \mathrm{C}$ in the dark. Cell-cycle analysis was performed at $488 \mathrm{~nm}$ using a Becton Dickinson (Franklin Lakes, NJ, USA) FACS Calibur flow cytometer. Apoptosis was determined by quantification of the pre-G1 peak. CellQuest was then used to analyse the data of 10000 gated cells once cell debris had been excluded. The data was stored as frequency histograms (Riccardi and Nicoletti, 2006).

\section{Western blot analysis}

SDS - polyacrylamide gel electrophoresis was performed as previously described (Bright et al, 2009). Briefly, whole-cell lysates were prepared in Laemmli buffer and run on an $8 \%$ gel. Equal protein loading was ensured by performing a BCA protein determination assay. Samples were then transferred to polyvinylidene difluoride membranes overnight, blocked in $5 \%(\mathrm{w} / \mathrm{v})$ marvel in Tris-buffered saline ( $\mathrm{pH} 7.6$ )/0.05\% Tween 20, incubated for $1 \mathrm{~h}$ with an anti-Abl or anti-Actin $\mathrm{mAb}$, washed, incubated for $1 \mathrm{~h}$ with a horseradish peroxidase-linked secondary $\mathrm{Ab}$ and washed again. Blots were developed using enhanced chemiluminescence and an automated developer (Fuji X-ray film processor, Fuji-Glasnevin, Dublin, Ireland). 


\section{Ex vivo $\mathrm{CML}$ patient samples and annexin $\mathrm{V}$ staining}

Peripheral blood $(10 \mathrm{ml})$ was collected with informed consent from newly diagnosed treatment naive $(n=4)$ or blast crisis imatinibresistant CML patients $(n=2)$ in EDTA-anticoagulant tubes. Ethical approval for all work carried out on ex vivo CML patient samples was obtained from the St. James's Hospital and Adelaide and Meath incorporating the National Children's Hospital Ethics Committee. Fresh blood was diluted 1:3 with unsupplemented RPMI medium and carefully added to half the equivalent volume of Lymphoprep. Samples were centrifuged at $750 \mathrm{~g}$ for $30 \mathrm{~min}$ to form a Ficoll gradient. The white buffy layer containing the white blood cells (WBCs) (or peripheral blood mononuclear cells) was carefully removed, diluted to a volume of $50 \mathrm{ml}$ with medium and centrifuged again for $10 \mathrm{~min}$ at $650 \mathrm{~g}$. White blood cells were then seeded at a density of $1 \times 10^{6}$ cells per $1 \mathrm{ml}$ medium in RPMI medium supplemented with $10 \%(\mathrm{v} / \mathrm{v})$ FBS, $1 \%(\mathrm{v} / \mathrm{v})$ L-glutamine and $50 \mu \mathrm{g} \mathrm{ml}^{-1}$ penicillin/streptomycin. After the required incubation, cells were centrifuged at $650 \mathrm{~g}$ for $5 \mathrm{~min}$, incubated in the dark at room temperature for $10 \mathrm{~min}$ with anti-CD45 antibody, centrifuged as before, washed in $1 \times$ annexin $\mathrm{V}$ binding buffer $(1 \mathrm{ml})$, centrifuged, labelled with Annexin $\mathrm{V}$ antibody on ice for $15 \mathrm{~min}$ in the dark, washed and finally resuspended them in $500 \mu \mathrm{l}$ Annexin $\mathrm{V}$ binding buffer. Leukaemic cells were then identified and gated by flow cytometry based on their low to medium side scatter and low CD45 expression, and apoptosis was analysed by annexin V staining (Lacombe et al, 1997).

\section{Mice}

Specific pathogen-free 6- to 8-week-old adult female BALB/c-nu/nu mice were purchased from Harlan Laboratories (Cambridgeshire, UK). Mice were housed in sterile individually ventilated cages, food and water were provided ad libitum, in accordance with the standard operating procedures set down in SI 17/94 of the European Union. Mice were acclimatised for 1 week before the initiation of any in vivo experiments. Animals were killed by $\mathrm{CO}_{2}$ if found to be in distress (hunching, failure to groom etc.) or if tumour volume exceeded $10 \%$ of mouse bodyweight. Ethical approval was obtained by the BioResources Committee, Trinity College, Dublin.

\section{In vivo tumour studies}

The in vivo antitumour efficacy of PBOX-6 was examined using a $\mathrm{Baf} / 3$ xenograft containing the T315I mutant of Bcr-Abl in a $\mathrm{BALB} / \mathrm{c}$ mouse model. Female BALB/c-nu/nu mice were inoculated subcutaneously (s.c.) into the right flank with $3 \times 10^{6} \mathrm{Baf} / 3$ cells in the log phase of growth. After 8 days, we observed that tumours had reached approximately $4 \mathrm{~mm}$ in diameter and we randomly divided mice into two groups. A stock solution of PBOX-6 was prepared at a concentration of $15 \mathrm{mg} \mathrm{ml}^{-1}$ in $1: 1$ ethanol/cremophor EL. When required, this was then diluted 1 in 5 in sterile PBS to give a final concentration of $7.5 \mathrm{mg} \mathrm{kg}^{-1}$ or $0.15 \mathrm{mg}$ per mouse. The treatment group $(n=6)$ received an intratumoural (i.t.) injection (Williams et al, 2007; Shah et al, 2009) of PBOX-6 once daily for the duration of the experiment starting on day 8. Control mice $(n=6)$ received a single daily i.t. injection of $50 \mu \mathrm{l}$ of the equivalent vehicle also starting on day 8 . Tumour growth was measured every second day with a sterile vernier calliper. The long $(L)$ and short $(S)$ axes were recorded, and tumour volume $(V)$ was calculated using the following equation as described previously (Beck et al, 2003).

$$
V=\frac{S^{2} \times L}{2}
$$

Mice were killed by $\mathrm{CO}_{2}$ asphyxiation at the experimental end point or if found to be under any excess duress.

\section{Statistical analysis}

The software Prism GraphPad (La Jolla, CA, USA) was used to carry out statistical analysis when comparing two samples using the Student's paired (ex vivo studies) or unpaired (in vivo studies) $t$-test. For illustrative purposes, the $P$-values are presented as $P<0.05$, * and $P<0.01$, ** respectively.

\section{RESULTS}

\section{Mutations in the Bcr-Abl gene confer varying degrees of} resistance to imatinib in transfected $\mathrm{Baf} / 3$ cell lines

The status of the Bcr-Abl protein in parental and transfected Baf/3 cells was confirmed by subjecting untreated cells to SDS-polyacrylamide gel electrophoresis and western blotting. Results confirmed the presence of the $\mathrm{Bcr}-\mathrm{Abl}$ protein in native cells and each of the mutant cell lines and absence of the protein in the parental, non-transformed Baf/3 cells (Figure 1A).

An AlamarBlue assay was used to show the varying effects of imatinib on each cell line. As expected, imatinib displayed the highest level of toxicity against the native cell line followed by the
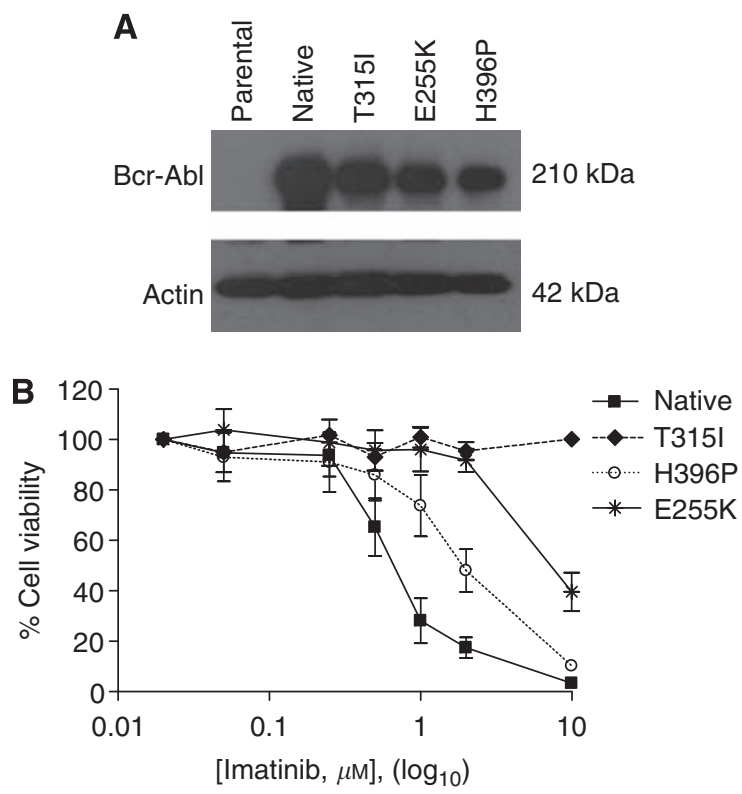

\begin{tabular}{|l|l|l|}
\hline & $\begin{array}{l}\text { IC50 } \\
(\text { imatinib }, \mu \mathrm{M})\end{array}$ & $\begin{array}{l}\text { Fold } \\
\text { difference }\end{array}$ \\
\hline Native & 0.658 & 1 \\
\hline T315I & N.D. & N.D. \\
\hline H396P & 1.9 & 2.9 \\
\hline E255K & 7.28 & 11.1 \\
\hline
\end{tabular}

Figure I Mutant Baf/3 cell lines containing the Bcr-Abl protein display varying degrees of resistance to imatinib when compared with the native cells. (A) Baf/3 cells were seeded during the log phase of growth and incubated for $24 \mathrm{~h}$. Samples were prepared for SDS-polyacrylamide gel electrophoresis and run on an $8 \%$ gel. Polyvinylidene difluoride membranes were incubated overnight with an anti-Bcr-Abl mAb. Actin is shown as a loading control. Results are representative of three independent experiments. (B) Cells were treated for $48 \mathrm{~h}$ with a vehicle (Veh) (0.01 \% DMSO) or a range of imatinib concentrations $(50 \mathrm{nM}-10 \mu \mathrm{M})$ in a 96 -well plate. After the incubation period, we added AlamarBlue dye $(20 \mu \mathrm{l})$ to each well and incubated samples for $3 \mathrm{~h}$. Cells were subsequently analysed for cell viability. Values represent the mean \pm s.e.m. of three independent experiments performed in triplicate. ND, not determined. 
H396P, E255K and finally the T315I mutant cell lines. Specifically, native cells were found to have an $\mathrm{IC}_{50}$ value of $658 \mathrm{~nm}$ towards imatinib. H396P cells were 2.9 times more resistant to imatinib than native cells whereas $\mathrm{E} 255 \mathrm{~K}$ cells were 11.1 times more resistant. The $\mathrm{IC}_{50}$ value for T315I cells could not be determined as these cells were found to be completely resistant to imatinib even at concentrations as high as $10 \mu \mathrm{m}$ (Figure 1B).

\section{PBOX compounds significantly reduce cell viability and} induce apoptosis in imatinib-resistant and native $\mathrm{Baf} / 3$ cell lines

The pro-apoptotic PBOX compounds were found to significantly reduce cell viability in all cell lines examined. Viability was reduced to $27.2 \pm 2.4,25.2 \pm 0.8,41.5 \pm 8.1$ and $48.7 \pm 6.1 \%$ in native, T315I, H396P and E255K cells treated with $25 \mu \mathrm{M}$ PBOX-6 (Figure 2A). PBOX-15 also significantly reduced cell viability in all the Bcr-Abl mutant Baf/3 cells. Specifically, PBOX-15 $(10 \mu \mathrm{M})$ reduced viability to $29.2 \pm 1.9,28.1 \pm 5.1,42.1 \pm 4.5$ and $40.7 \pm 4.6 \%$ in native, T315I, H396P and E255K, respectively (Figure 2B).

As the PBOX compounds caused similar effects against all the mutations tested, it was decided to focus our attention on the T315I mutation that conferred the highest degree of resistance to imatinib. Flow cytometry results showed that PBOX-6 and PBOX-15 induced similar levels of apoptosis (Figure 2C) in both native and T315I cells. PBOX-6 also caused a similar number of cells to undergo a sustained $\mathrm{G} 2 / \mathrm{M}$ arrest, with the percentage of cells in the G2/M phase increasing from $23.7 \pm 2.1$ and $16.9 \pm 2.1 \%$ to $43.7 \pm 4.0$ and $37.5 \pm 7.5 \%$ in WT and T315I cells, respectively (Figure 2D).

The PBOX compounds were also evaluated for their effects on parental non-transfected $\mathrm{Baf} / 3$ cells, whereas the compounds did induce some toxicity on these cells (data not shown) it should be noted that the cells had been artificially stimulated using IL-3 to produce actively dividing cells. However, B cells in vivo are not actively cycling and are therefore unlikely to be affected by the compounds.

\section{PBOX compounds induce apoptosis in ex vivo samples from newly diagnosed and imatinib-resistant blast crisis phase CML patients}

The advent of cell lines has allowed us to gain insight into many molecular signalling pathways; they are a useful tool to help develop novel therapeutic anticancer agents. However as cell lines have been engineered to continuously and consistently divide, they do not fully represent primary leukaemia cells. For this reason, it is necessary to confirm the effects of potentially novel therapeutics found in cell lines on ex vivo patient samples. For this, we obtained informed consent from a cohort of newly diagnosed and treatment naive CML patients along with those that had refractory disease. Annexin V staining was then used to identify apoptotic cells. Patient samples 1-4 were newly diagnosed CML patients who subsequently responded well to either imatinib or nilotinib, none have since progressed to later stages of CML. Patient samples 5 and 6 were obtained from imatinib- and dasatinib-insensitive patients in blast crisis (Table 1). Patient 5 tested $100 \%$ positive for the T315I mutation at time of death that occurred approximately 1 month after sample collection, whereas patient 6 who is currently on nilotinib treatment tested $100 \%$ positive for the F317l mutation at the time of sample collection and had a minor T315I mutant clone.

White blood cells were isolated from freshly obtained blood samples, seeded and treated for $72 \mathrm{~h}$ with a PBOX compound $(25 \mu \mathrm{M}$ PBOX-6 or $10 \mu \mathrm{M}$ PBOX-15) or $250 \mathrm{nM}$ imatinib, a physiologically relevant concentration of STI571. Leukaemic cells
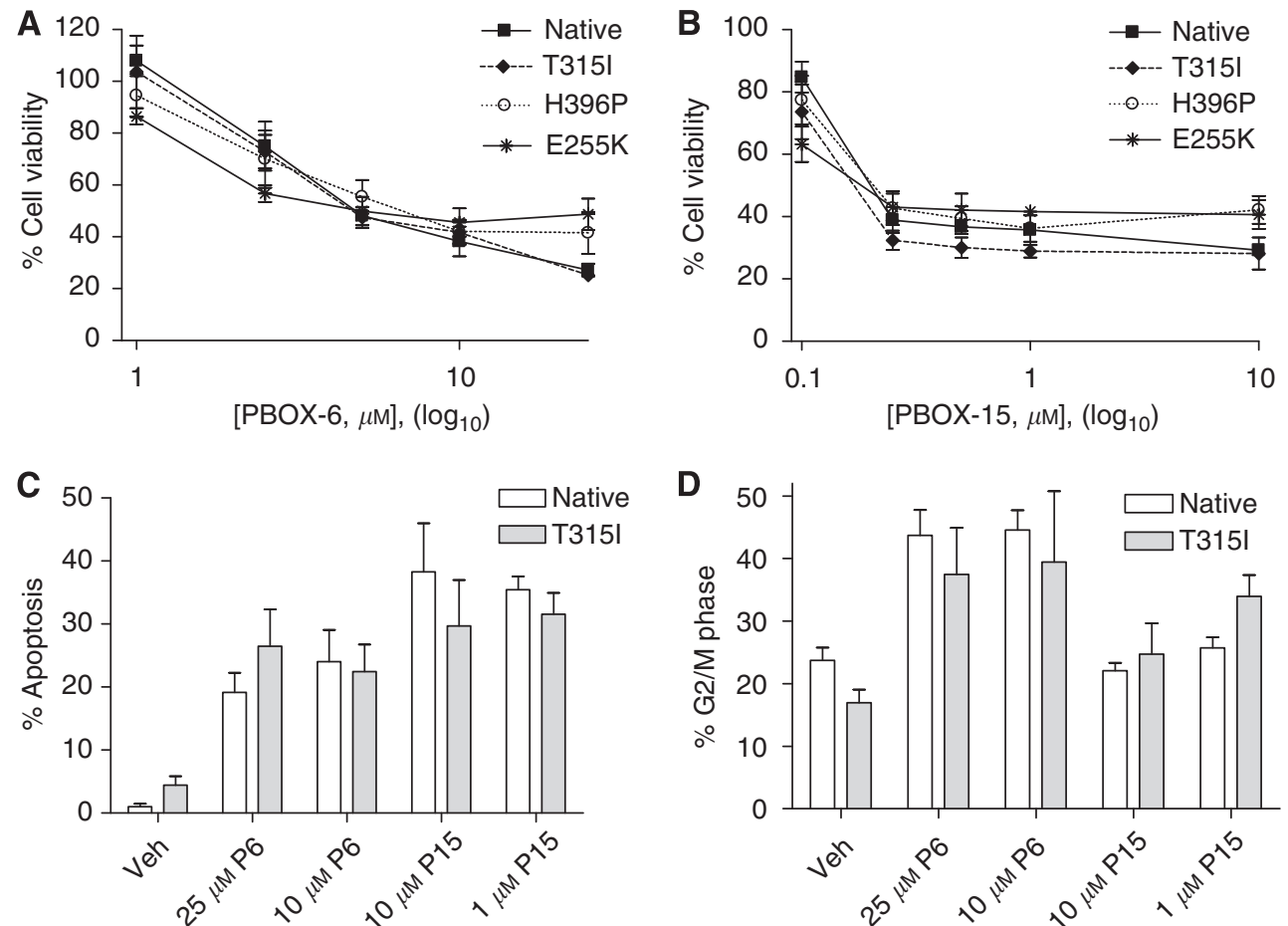

Figure 2 PBOX-6 and PBOX-I5 reduce cell viability and induce apoptosis equipotently in native and T3I5I Baf/3 cell lines. Native and Bcr-Abl mutant Baf/3 cells were seeded during the log phase of growth and treated for $48 \mathrm{~h}$ with a vehicle $(\mathrm{I} \% \mathrm{(v/ \textrm {v } )}$ ethanol) (Veh) or with the indicated concentrations of PBOX-6 or PBOX-I5 (P6, P I 5). After the incubation period, we assessed cells for (A and $\mathbf{B})$ cell viability by the AlamarBlue viability assay, (C) apoptosis by quantification of the pre-GI peak and (D) the percentage of cells in the G2/M phase. Values represent the mean \pm s.e.m. of three independent experiments performed in triplicate. 
Table I Characteristics of CML patients in ex vivo study

\begin{tabular}{|c|c|c|c|c|c|}
\hline No. & Sex & Age & Disease status & CML treatment & Current status \\
\hline I & M & 46 & Newly diagnosed & Imatinib & Currently on imatinib, CCR within first year treatment \\
\hline 2 & $\mathrm{~F}$ & 31 & Newly diagnosed & Imatinib & Currently on imatinib, CCR within first year treatment \\
\hline 3 & M & 26 & Newly diagnosed & Nilotinib (as part of clinical trial) & Currently on nilotinib, MCR in first 3 months treatment \\
\hline 4 & $\mathrm{~F}$ & 42 & Newly diagnosed & Nilotinib (as part of clinical trial) & Currently on nilotinib, MCR in first 3 months treatment \\
\hline 5 & $\mathrm{~F}$ & 73 & Blast crisis & Failed imatinib+dasatinib treatment & Deceased, $100 \%$ positive for $\mathrm{T} 3151$ mutation at time of death \\
\hline 6 & $\mathrm{~F}$ & 62 & Blast crisis & Failed imatinib+dasatinib treatment & $\begin{array}{l}\text { Currently on nilotinib, } 100 \% \text { positive for } \mathrm{F} 3 \mathrm{I} 7 \mathrm{I} \\
\text { mutation and minor } \mathrm{T} 3 \mathrm{I} 5 \mathrm{I} \text { clone at time of sample collection }\end{array}$ \\
\hline
\end{tabular}

Abbreviations: $\mathrm{CCR}=$ a complete cytogenetic response means that no blood or bone marrow cells contain the $\mathrm{Ph}$ chromosome; $\mathrm{CML}=$ chronic $\mathrm{myeloid}$ leukaemia; $\mathrm{M}=$ male; $\mathrm{F}=$ female; $\mathrm{MCR}=$ a major (or partial) cytogenetic response the presence of less than $35 \%$ Bcr-Abl-positive cells. Relevant medical and personal data were obtained from newly diagnosed and imatinib-resistant CML patients enrolled in an ex vivo PBOX study carried out in St. James's Hospital, Dublin 8 in collaboration with Dr. Eibhlin Conneally and Professor Mark Lawler. Information obtained included the sex of the patient, age at diagnosis and a short description of their medical and CML-specific treatment.
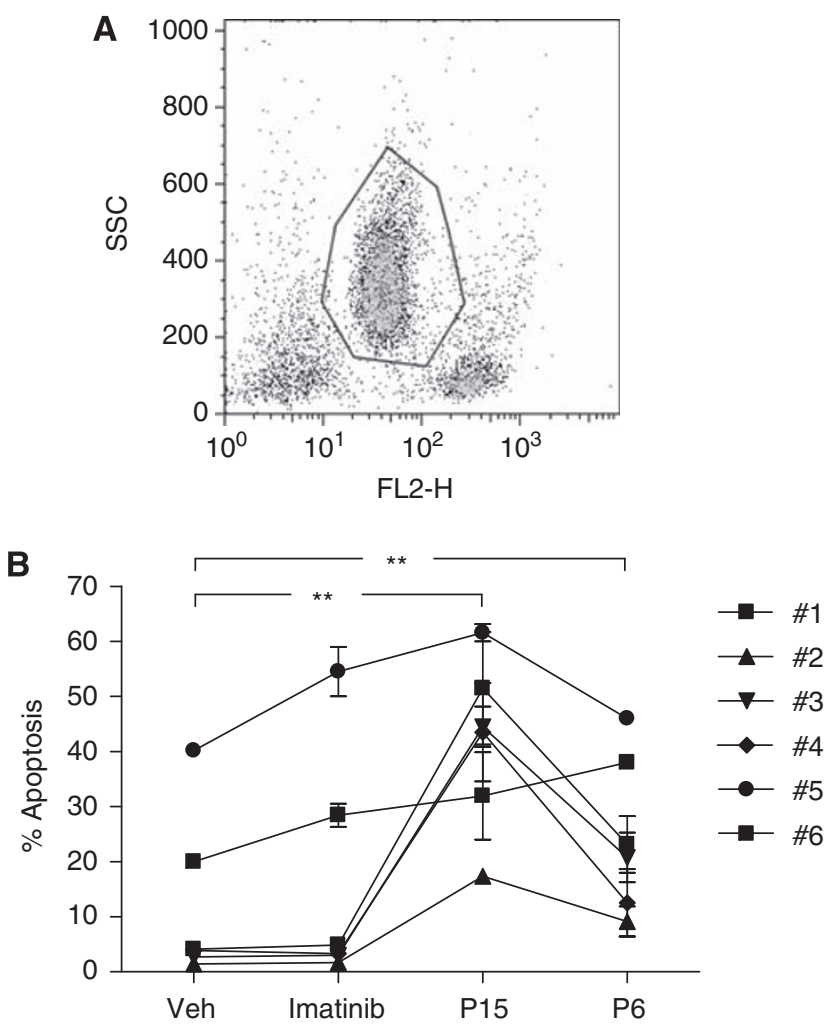

Figure 3 Isolation of leukaemic cells from CML patient blood samples. White blood cells were isolated from the fresh peripheral blood of $C M L$ patients $(n=6)$ by Ficoll gradient. Cells were seeded at a density of $1 \times 10^{6}$ cells per $\mathrm{ml}$ in 24-well plates and treated with a vehicle (Veh) $(1 \%(\mathrm{~V} / \mathrm{V})$ ethanol or $0.0025 \%$ (v/v) DMSO), $10 \mu \mathrm{M}$ PBOX-I 5 (PI5), $25 \mu \mathrm{M}$ PBOX-6 (P6) or $250 \mathrm{nM}$ imatinib for $72 \mathrm{~h}$. Cells were then labelled with an antiCD45 antibody and FITC-annexin V and analysed by flow cytometry. Leukaemic cells were identified and gated based on their low to medium side scatter and low CD45 expression. (A) A representative dot plot of CD45-stained vehicle-treated cells is shown. (B) Percentage of cells undergoing apoptosis as determined by annexin-V-positive staining. Experiments were performed in duplicate. Statistical analysis was performed using the Student's paired t-test, ${ }^{*} * P<0.0$ I.

were identified by their low to medium side scatter and low CD45 expression after annexin $\mathrm{V}$ staining (Figure 3A).

Collectively, when all samples were combined, PBOX-6 induced $24.7 \pm 5.0 \%$ apoptosis ( $P$-value: $\left.0.0050,{ }^{\star *}\right)$ whereas PBOX-15 induced $39.5 \pm 5.8 \%$ apoptosis ( $P$-value: $0.0059, * *)$ compared with background levels of apoptosis of $13.4 \pm 5.5 \%$ in control samples.
There was no significant difference between the control and the imatinib-treated samples that underwent $18.2 \pm 7.7 \%$ apoptosis (Figure 3B). This may have been due to the inclusion of the two imatinib-resistant patient samples. No individual sample showed a lack of response to either PBOX-6 or PBOX-15.

\section{PBOX-6 administration significantly inhibits tumour growth in a CML mouse model of the imatinib-resistant T315I mutants}

Five- to six-week-old female BALB/c-nude mice were inoculated s.c. into the right flank with $3 \times 10^{6} \mathrm{Baf} / 3-\mathrm{T} 315 \mathrm{I}$ cells in the log phase of growth. Tumours started to appear by day $5 / 6$ and were measurable by day 8 . Mice were divided into groups with small-, medium- and larger-sized tumours and then further randomly divided into two groups $(n=6)$ to ensure the average tumour size was equal for both groups. One group received daily i.t. injections of $7.5 \mathrm{mg} \mathrm{kg}^{-1}$ PBOX- 6 whereas the other group received a vehicle $(10 \%(\mathrm{v} / \mathrm{v})$ ethanol and $10 \%(\mathrm{v} / \mathrm{v})$ cremophor EL in PBS).

Results showed that PBOX-6 did not adversely affect weight. In fact, both groups put on a small amount of weight during the experiment increasing from $14.7 \pm 0.7$ and $14.8 \pm 0.6 \mathrm{~g}$ to $16.5 \pm 0.8$ and $16.5 \pm 0.3 \mathrm{~g}$ in control and PBOX-treated groups, respectively. This would be expected with healthy mice of such an age (Figure 4A). Close inspection of mice also ensured that no mouse suffered any form of distress such as failing to groom, hunching.

Tumour growth was measured every second day, the long $(L)$ and short $(S)$ axes were recorded, and tumour volume $(V)$ calculated using the following equation: $V=\left(S^{2} \times L\right) / 2$ (Beck et al, 2003). Injections were initiated on day 8 when there was no significant difference in tumour volume between the control and the PBOX-treated groups. By day 10, PBOX-6 had significantly reduced tumour growth when compared to control group. Tumour burden was continuously and significantly inhibited up until the experimental end point (Figure 4B). Statistical analysis was performed using an unpaired Student's $t$-test.

At the experimental end point, day 18, mice were killed by $\mathrm{CO}_{2}$ asphyxiation and a splenectomy was performed. The vehicle-treated group showed gross enlargement of spleens, or splenomegaly a clinical symptom of advanced disease, when compared to the PBOX-6-treated group, with a 3.7-fold increase in weight from $163.3 \pm 39.51$ to $608.7 \pm 105.3 \mathrm{mg}$ ( $P$-value: $\left.0.0027,{ }^{* *}\right)$ (Figure 4C). This is likely to be due to the reduced tumour burden of PBOX-treated animals.

\section{DISCUSSION}

Our group has recently developed a novel set of compounds known as the PBOXs that actively induce apoptosis in numerous haematological cancers and solid tumours (Zisterer et al, 2000, 
A

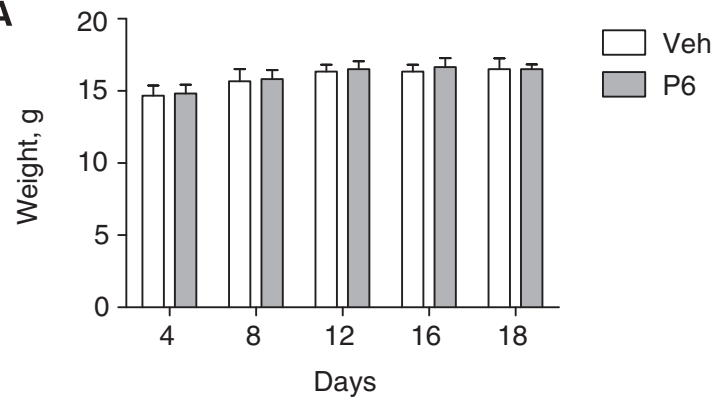

B

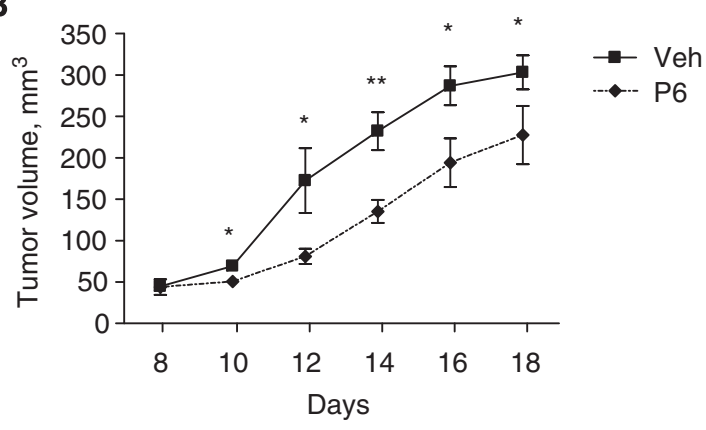

C

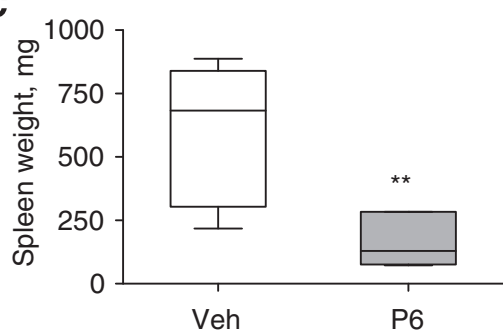

Figure 4 Administration of $\mathrm{PBOX}-6$ significantly inhibits tumour growth and prevents gross spleen enlargement in an in vivo mouse model of $\mathrm{CML}$ harboring the T3I5I mutation. Five- to six-week-old female BALB/c-nude (nu/nu) mice were inoculated s.c. into the right flank with $3 \times 10^{6} \mathrm{Baf} / 3$ $\mathrm{Bcr}-\mathrm{Abl}-\mathrm{T} 3 \mathrm{I} 5 \mathrm{I}$ cells in the log phase of growth. When tumours had reached a diameter of $\sim 4 \mathrm{~mm}$ (day 8), mice were randomly divided into two treatment groups $(n=6)$ and received daily i.t. injections of PBOX-6 (P6) $\left(7.5 \mathrm{mg} \mathrm{kg}^{-1}\right)$ or a vehicle (Veh) (10\% (v/v) cremophor, $10 \%(\mathrm{v} / \mathrm{v})$ ethanol in PBS). (A) Mice were weighed every 4 days and at the experimental end point (day 18). (B) Tumour growth was measured every second day, the long $(L)$ and short $(S)$ axes were recorded, and tumour volume $(V)$ calculated using the equation: $V=\left(S^{2} \times L\right) / 2$ (Beck et al., 2003). (C) Mice were killed on day 18, spleens were removed and weighed. Statistical analysis was performed using the Student's unpaired $t$-test, $* P<0.05$; *** $P<0.01$.

2001; Mc Gee et al, 2004; Mulligan et al, 2006). Representative compounds have recently been shown to induce apoptosis in ex vivo CLL patient samples including samples that are composed of cells with poor prognostic markers such as fludarabine-resistant cells with chromosomal deletions in 17p (McElligott et al, 2009). Furthermore, an in vivo study by our group has previously shown PBOX-6 to exhibit antitumour activity in a murine breast tumour model (Greene et al, 2005) highlighting their potential as novel anticancer agents. Recent data also suggest the PBOX compounds show activity in MDR cell lines by bypassing P-gp (Nathwani et al, 2009).

The tyrosine kinase inhibitor imatinib has revolutionised CML treatment since its regulatory approval in 2001 (Deininger and Druker, 2003). In spite of this success, disease progression into a fatal acute leukaemia still occurs. Disease progression is commonly associated with mutations within the kinase domain of Bcr-Abl that result in varying degrees of resistance to imatinib, these mutations have been identified as the major mechanism of acquired imatinib resistance. Therefore, the search for alternative drug treatments capable of overcoming such resistance is crucially important (O'Hare et al, 2007). For this reason, we analysed the effects of the PBOX compounds on CML cells harbouring such mutations.

The amino-acid mutations chosen for this study represented several functionally distinct kinase domain regions, including the P-loop (E255K), the site of a hydrogen bond with imatinib (T315I) and the activation loop (H396P) (Griswold et al, 2006). Transfected cells were first subjected to analysis by western blot and confirmed the presence of the Bcr-Abl protein. A viability assay showed that the mutant $\mathrm{Bcr}-\mathrm{Abl}$ cells, displayed as expected, varying degrees of resistance to imatinib of between 2.9- and 11.1-fold for H396P and E255K cells, respectively, when compared to native cells. T315I cells showed complete resistance to concentrations of imatinib as high as $10 \mu \mathrm{M}$. IC 50 values and resistance fold difference could not therefore be determined for these cells. However, a previous report suggests an $\mathrm{IC}_{50}$ value of $18 \mu \mathrm{m}$ for Bcr-Abl-T315I cells treated with imatinib (Chen et al, 2006).

In comparison to the wide range of effects of imatinib on the viability of Bcr-Abl mutants, PBOX- 6 and PBOX-15 reduced the viability to a similar extent in all four cell lines. The clones harbouring these mutations, particularly the prevalent mutations E255K and T315I, have been shown to exist before imatinib treatment (Roche-Lestienne et al, 2002, 2003; Shah et al, 2002; Hofmann et al, 2003; Kreuzer et al, 2003) and are associated with enhanced kinase activities and proliferation rates (Yamamoto et al, 2004; Griswold et al, 2006). Mutations such as E255K are also associated with significantly shorter survival rates than other mutations, regardless of their sensitivity to imatinib (Griswold et al, 2006), resulting in a more aggressive phenotype. This highlights the importance of the PBOX compounds in overcoming these aggressive mutations. The apoptotic effects of the PBOX compounds have also been shown to be irreversible, a recent study on the CML cell line, K562, has shown the PBOX compounds to continue to induce apoptosis $24 \mathrm{~h}$ after cells have been washed free of the compounds (Bright et al, 2010).

One of the most common Bcr-Abl mutations found in CML patients is the T315I mutation. Many imatinib-resistant mutants are sensitive to second-generation inhibitors such as dasatinib and nilotinib; however, the T315I mutation remains insensitive to both drugs (O'Hare et al, 2007; Quintás-Cardama and Cortes, 2008b). Thus, it was decided to concentrate our efforts on the T315I mutation for further analysis. Results showed PBOX-6 and PBOX-15 to induce similar levels of apoptosis in native and T315I mutant cells, suggesting that these agents are capable of overcoming imatinib resistance irrespective of $\mathrm{Bcr}-\mathrm{Abl}$ genotype.

Although there are numerous reports of novel compounds effective at inducing apoptosis in T315I-expressing cells in the literature, many are at a pre-clinical stage such as ON012380 a non-competitive ATP inhibitor (Gumireddy et al, 2005), SGX393 a direct Bcr-Abl inhibitor (O'Hare et al, 2008) and the histone deacetylase inhibitor LAQ824 (Weisberg et al, 2004). Compounds that have displayed activity against the T315I mutants in clinical trials include the aurora kinase inhibitor MK-0457 (Giles et al, 2007) and homoharringtonine that inhibits protein synthesis (Quintás-Cardama and Cortes, 2008a). Other compounds currently undergoing clinical assessment but whose antitumour activity in patients has yet to be fully determined include the histone deacetylase inhibitors SAHA and LBH589, the farnesyltransferase inhibitor BMS-214662 and the aurora kinase inhibitors PHA-739358 and AT-9283 among others (Tanaka and Kimura, 2008; QuintásCardama and Cortes, 2008b). However, to date no compound with activity against the T315I mutation has made it through trials and onto the clinical market.

Although the effects of the PBOXs on $\mathrm{Bcr}-\mathrm{Abl}$ mutations in vitro is clear, these results needed to be confirmed in ex vivo patient 
samples, critically important in predicting a clinical response to potential anticancer drugs. Of the newly diagnosed patients enlisted for PBOX evaluation, all ex vivo samples analysed (4 out of 4) displayed a significant increase in apoptosis after PBOX-6 and PBOX-15 treatment when compared with imatinib and control treatments. Half of these patients ( 2 out of 4$)$ are currently on the front-line treatment for chronic phase CML, imatinib treatment, with the other half on nilotinib treatment as part of a clinical trial. These results suggest a potential role for the pro-apoptotic PBOX compounds in the treatment of newly diagnosed CML patients. Similar enhancements in apoptosis were also observed in two imatinib-resistant ex vivo samples both of whom tested positive for the T315I mutation. Although the low levels of the T315I mutation in patient 6 are unlikely to have contributed significantly to in vitro resistance, this patient also tested $100 \%$ positive for the $\mathrm{F} 317 \mathrm{l}$ mutation, another highly imatinib-resistant mutation, suggesting the PBOX compounds also successfully induce apoptosis in cells harbouring this mutation. Although the number of primary samples obtained is limited and no firm conclusions can be drawn from the data of just two imatinib-resistant patients, these positive results do warrant a larger study assessing the effects of the PBOX compounds on further imatinib-insensitive primary samples to be undertaken.

Notably, the PBOX compounds do not display cytotoxicity in blood samples obtained from healthy volunteers (Mc Gee et al, 2004; Greene et al, 2007; McElligott et al, 2009). Furthermore, a low level of vasorelaxing activity and a lack of inhibition of nitrendipine binding, both measures of calcium antagonism suggest a general lack of cardiotoxicity of the PBOX compounds (DMZ, unpublished data). A lack of in vivo toxicity was also observed in unchallenged Balb/c mice administered for 8 days with PBOX-6 as determined by analysis of the haematology parameters of platelets, WBCs and red blood cells when compared to vehicletreated mice (DMZ, unpublished data).

The PBOX compounds are not just specific for Bcr-Abl-positive cells but are also specific for a wide variety of cancerous cells. The molecular target of the PBOX compounds has recently been identified as tubulin and differences between the tubulin properties of cancer and non-cancer cells may therefore be responsible for the preference of the compounds for cancer cells. The compounds have been shown to bind to a novel, as yet uncharacterised binding site on tubulin (Mulligan et al, 2006) and work is currently underway to characterise this binding site using $\mathrm{X}$-ray crystallography. This will give further insight into the exact mechanism of action and specificity of the compounds.

After the demonstration that the PBOX compounds induce apoptosis in vitro and in ex vivo patient samples, we next sought to determine the effects of the PBOX compounds in an in vivo CML xenograft model. The xenotransplant model has also been successfully used for the preliminary pre-clinical drug testing of
SCH66336 and SXG393 (Peters et al, 2001; O'Hare et al, 2008) and although this model is not without limitations it does enable the effective testing of the compounds on the T315I mutation in vivo. Although PBOX-15 showed more potent activity in primary samples, PBOX-6 was chosen as a representative PBOX compound for in vivo testing as it has previously been shown to restrict tumour growth in an in vivo mouse mammary carcinoma (Greene et al, 2005). It remains to be seen whether PBOX-15 shows activity in vivo. Female Balb/c nude mice were injected s.c. with $\mathrm{Baf} / 3$ T315I CML cells and randomly divided into two treatment groups. Results showed that PBOX-6 significantly impeded tumour growth while also preventing gross spleen enlargement when compared to mice receiving vehicle injections. Mice did not experience weight loss or exhibit any signs of distress during PBOX treatment suggesting PBOX-6 to be a viable anticancer agent in vivo. Although the control group also appeared to gain some weight throughout the experiment, this may have been due to the increase in spleen weight rather than natural growth.

Although tumour growth was significantly reduced, the tumour mass did still increase over the duration of the experiment; however, the results from this and previous research suggest the true potential of the PBOX compounds in vivo could lie in their combination with other anticancer compounds, recent data have shown the ability of the PBOXs to synergise with other compounds including imatinib and the CDK1 inhibitor flavopiridol. (Greene et al, 2007; Bright et al, 2009, 2010). Future studies looking at the activity of the PBOX compounds in combination with these agents in vivo are planned, as are advanced models that more readily replicate the disease in vivo, such as the retroviral CML mouse model. Ongoing work with a collaborating laboratory, looking at the design and synthesis of 'second-generation' more potent PBOX compounds could potentially further increase the activity of the compounds.

In conclusion, the PBOX compounds significantly reduced the cell viability of CML cells lines harbouring the E225K, H396P and T315I Bcr-Abl mutations. Both PBOX-15 and PBOX-6 significantly increased the number of cells undergoing apoptosis in native and T315I cells in vitro and in ex vivo patient samples whereas PBOX-6 also significantly reduced tumour burden in a mouse xenograft model. These results underline the potential of the PBOX compounds in the clinical treatment of CML patients including those who develop the highly resistant T315I mutant.

\section{ACKNOWLEDGEMENTS}

We thank Elisabeth Buchdunger, Novartis for providing the imatinib. This work was supported by Science Foundation Ireland and Cancer Research Ireland.

\section{REFERENCES}

Apperley JF (2007a) Part I: mechanisms of resistance to imatinib in chronic myeloid leukaemia. Lancet Oncol 8: 1018-1029

Apperley JF (2007b) Part II: management of resistance to imatinib in chronic myeloid leukaemia. Lancet Oncol 8: 1116-1128

Beck MT, Chen NY, Franek KJ, Chen WY (2003) Experimental therapeutics prolactin antagonist-endostatin fusion protein as a targeted dualfunctional therapeutic agent for breast cancer. Cancer Res 63: 3598-3604

Borthakur G, Kantarjian H, Daley G, Talpaz M, O'Brien S, Garcia-Manero G, Giles F, Faderl S, Sugrue M, Cortes J (2006) Pilot study of lonafarnib, a farnesyl transferase inhibitor, in patients with chronic myeloid leukemia in the chronic or accelerated phase that is resistant or refractory to imatinib therapy. Cancer 106: $346-352$

Bright SA, Campiani G, Deininger MW, Lawler M, Williams DC, Zisterer DM (2010) Flavopiridol synergistically enhances pyrrolo-1,5-benzoxaze- pine-induced apoptosis in human chronic myeloid leukaemia cells in a sequence dependent manner. Biochem Pharmacol; doi:10.1016/j.bcp. 2010.02.019

Bright SA, Greene LM, Greene TF, Campiani G, Butini S, Brindisi M, Lawler M, Meegan MJ, Williams DC, Zisterer DM (2009) The novel pyrrolo-1, 5-benzoxazepine, PBOX-21, potentiates the apoptotic efficacy of STI571 (imatinib mesylate) in human chronic myeloid leukaemia cells. Biochem Pharmacol 77: $310-321$

Capdeville R, Buchdunger E, Zimmermann J, Matter A (2002) Glivec (STI571, Imatinib), a rationally developed, targeted anticancer drug. Nat Rev Drug Discov 1: 493-502

Chen R, Gandhi V, Plunkett W (2006) A sequential blockade strategy for the design of combination therapies to overcome oncogene addiction in chronic myelogenous leukemia. Cancer Res 66: 10959-10966 
Deininger M, Buchdunger E, Druker B (2005) The development of imatinib as a therapeutic agent for chronic myeloid leukemia. Blood 105: $2640-2653$

Deininger M, Druker B (2003) Specific targeted therapy of chronic myelogenous leukemia with imatinib. Pharmacol Rev 55: 401-423

Deininger M, Goldman J, Melo J (2000) The molecular biology of chronic myeloid leukemia. Blood 96: 3343-3356

Druker B, Sawyers C, Capdeville R, Ford J, Baccarani M, Goldman J (2001) Chronic myelogenous leukemia. Hematology (Am Soc Hematol Educ Program) 1: 87-112

Fiskus W, Pranpat M, Balasis M, Bali P, Estrella V, Kumaraswamy S, Rao R, Rocha K, Herger B, Lee F, Richon V, Bhalla K (2006a) Cotreatment with vorinostat (suberoylanilide hydroxamic acid) enhances activity of dasatinib (BMS-354825) against imatinib mesylate-sensitive or imatinib mesylate-resistant chronic myelogenous leukemia cells. Clin Cancer Res 12: $5869-5878$

Fiskus W, Pranpat M, Bali P, Balasis M, Kumaraswamy S, Boyapalle S, Rocha K, Wu J, Giles F, Manley PW, Atadja P, Bhalla K (2006b) Combined effects of novel tyrosine kinase inhibitor AMN107 and histone deacetylase inhibitor LBH589 against Bcr-Abl-expressing human leukemia cells. Blood 108: $645-652$

Giles FJ, Cortes J, Jones D, Bergstrom D, Kantarjian H, Freedman SJ (2007) MK-0457, a novel kinase inhibitor, is active in patients with chronic myeloid leukemia or acute lymphocytic leukemia with the T315I BCR-ABL mutation. Blood 109: 500-502

Greene LM, Fleeton M, Mulligan J, Gowda C, Sheahan BJ, Atkins GJ, Campiani G, Nacci V, Lawler M, Williams DC, Zisterer DM (2005) The pyrrolo-1,5-benzoxazepine, PBOX-6, inhibits the growth of breast cancer cells in vitro independent of estrogen receptor status and inhibits breast tumour growth in vivo. Oncol Rep 14: 1357-1363

Greene LM, Kelly L, Onnis V, Campiani G, Lawler M, Williams DC, Zisterer DM (2007) STI-571 enhances the apoptotic efficacy of PBOX-6, a novel microtubule targeting agent, in both STI-571- sensitive and -resistant Bcr-Abl-positive human chronic myeloid leukemia cells. J Pharmacol Exp Ther 321: $288-297$

Griswold IJ, MacPartlin M, Bumm T, Goss VL, O'Hare T, Lee KA, Corbin AS, Stoffregen EP, Smith C, Johnson K, Moseson EM, Wood LJ, Polakiewicz RD, Druker BJ, Deininger MW (2006) Kinase domain mutants of Bcr-Abl exhibit altered transformation potency, kinase activity, and substrate utilization, irrespective of sensitivity to imatinib. Mol Cell Biol 26: 6082-6093

Guilhot F, Apperley J, Kim D, Bullorsky E, Baccarani M, Roboz G, Amadori S, de Souza C, Lipton J, Hochhaus A, Heim D, Larson R, Branford S, Muller M, Agarwal P, Gollerkeri A, Talpaz M (2007) Dasatinib induces significant hematologic and cytogenetic responses in patients with imatinib-resistant or -intolerant chronic myeloid leukemia in accelerated phase. Blood 109: 4143-4150

Gumireddy K, Baker SJ, Cosenza SC, John P, Kang AD, Robell KA, Reddy MVR, Reddy EP (2005) A non-ATP-competitive inhibitor of BCR-ABL overrides imatinib resistance. Proc Natl Acad Sci USA 102: 1992-1997

Hofmann WK, Komor M, Wassmann B, Jones LC, Gschaidmeier H, Hoelzer D, Koeffler HP, Ottmann OG (2003) Presence of the BCR-ABL mutation E255K prior to STI571 (imatinib) treatment in patients with $\mathrm{Ph}+$ acute lymphoblastic leukemia. Blood 102: 659-661

Hughes T, Deininger M, Hochhau A, Branford S, Radich J, Kaeda J, Baccarani M, Cortes J, Cross NC, Druker BJ, Gabert J, Grimwade D, Hehlmann R, Kamel-Reid S, Lipton JH, Longtine J, Martinelli G, Saglio G, Soverini S, Stock W, Goldman JM (2006) Monitoring CML patients responding to treatment with tyrosine kinase inhibitors: review and recommendations for harmonizing current methodology for detecting BCR-ABL transcripts and kinase domain mutations and for expressing results. Blood 108: $28-37$

Kelly W, Richon V, O'Connor O, Curley T, MacGregor-Curtelli B, Tong W, Klang M, Schwartz L, Richardson S, Rosa E, Drobnjak M, Cordon-Cordo C, Chiao J, Rifkind R, Marks P, Scher H (2003) Phase I clinical trial of histone deacetylase inhibitor: suberoylanilide hydroxamic acid administered intravenously. Clin Cancer Res 10: 3578-3588

Kreuzer KA, Le Coutre P, Landt O, Na IK, Schwarz M, Schultheis K, Hochhaus A, Dorken B (2003) Preexistence and evolution of imatinib mesylate-resistant clones in chronic myelogenous leukemia detected by a PNA-based PCR clamping technique. Ann Hematol 82: 284-289

Lacombe F, Durrieu F, Briais A, Dumain P, Belloc F, Bascans E, Reiffers J, Boisseau MR, Bernard P (1997) Flow cytometry CD45 gating for immunophenotyping of acute myeloid leukemia. Leukemia 11: $1878-1886$
Mahon F, Deininger M, Schultheis B, Chabrol J, Reiffers J, Goldman J, Melo J (2000) Selection and characterization of BCR-ABL positive cell lines with differential sensitivity to the tyrosine kinase inhibitor STI571: diverse mechanisms of resistance. Blood 96: 1070-1079

Mc Gee MM, Campiani G, Ramunno A, Fattorusso C, Nacci V, Lawler M, Williams DC, Zisterer DM (2001) Pyrrolo-1 5-benzoxazepines induce apoptosis in chronic myelogenous leukemia (CML) cells by bypassing the apoptotic suppressor bcr-abl. J Pharmacol Exp Ther 296: 31-40

Mc Gee MM, Greene LM, Ledwidge S, Campiani G, Nacci V, Lawler M, Williams DC, Zisterer DM (2004) Selective induction of apoptosis by the pyrrolo-1,5-benzoxazepine 7-[[dimethylcarbamoyl]oxy]-6-(2-naphthyl)pyrrolo-[2,1-d] (1,5)-benzoxazepine (PBOX-6) in leukemia cells occurs via the c-Jun NH2-terminal kinase-dependent phosphorylation and inactivation of Bcl-2 and Bcl-XL. J Pharmacol Exp Ther 310: 1084- 1095

McElligott AM, Maginn EN, Greene LM, McGuckin S, Hayat A, Browne PV, Butini S, Campiani G, Catherwood MA, Vandenberghe E, Williams DC, Zisterer DM, Lawler M (2009) The novel tubulin-targeting agent pyrrolo1,5-benzoxazepine-15 induces apoptosis in poor prognostic subgroups of chronic lymphocytic leukemia. Cancer Res 69: 8366-8375

McFarland KL, Wetzstein GA (2009) Chronic myeloid leukemia therapy: focus on second-generation tyrosine kinase inhibitors. Cancer Control 16: $132-140$

Mulligan JM, Greene LM, Cloonan S, Mc Gee MM, Onnis V, Campiani G, Fattorusso C, Lawler M, Williams DC, Zisterer DM (2006) Identification of tubulin as the molecular target of proapoptotic pyrrolo-1,5benzoxazepines. Mol Pharmacol 70: 60-70

Nakajima A, Tauchi T, Sumi M, Bishop W, Ohyashiki K (2003) Efficacy of SCH66336, a farnesyl transferase inhibitor, in conjunction with imatinib against BCR-ABL-positive cells. Mol Cancer Ther 2: 225-226

Nathwani SM, Butler S, Fayne D, McGovern NN, Sarkadi B, Meegan MJ, Lloyd DG, Campiani G, Lawler M, Williams DC, Zisterer DM (2009) Novel microtubule-targeting agents, pyrrolo-1,5-benzoxazepines, induce apoptosis in multi-drug-resistant cancer cells. Cancer Chemother Pharmacol; doi:10.1007/s00280-1009-1200-9

Nguyen T, Rahmani M, Gao N, Kramer L, Corbin A, Druker B, Dent P, Grant $S$ (2006) Synergistic interactions between DMAG and mitogen-activated protein kinase kinase 1/2 inhibitors in Bcr/abl+ leukemia cells sensitive and resistant to imatinib mesylate. Clin Cancer Res 12: 2239-2247

O'Hare T, Eide CA, Deininger MW (2007) Bcr-Abl kinase domain mutations, drug resistance, and the road to a cure for chronic myeloid leukemia. Blood 110: 2242-2249

O'Hare T, Eide CA, Tyner JW, Corbin AS, Wong MJ, Buchanan S, Holme K, Jessen KA, Tang C, Lewis HA, Romero RD, Burley SK, Deininger MW (2008) SGX393 inhibits the CML mutant Bcr-AblT315I and preempts in vitro resistance when combined with nilotinib or dasatinib. Proc Natl Acad Sci USA 105: 5507-5512

Peters D, Hoover R, Gerlach M, Koh E, Zhang H, Choe K, Kirschmeier P, Bishop W, Daley G (2001) Activity of the farnesyl protein transferase inhibitor SCH66336 against BCR/ABL-induced murine leukemia and primary cells from patients with chronic myeloid leukemia. Blood 97: $1404-1412$

Quintás-Cardama A, Cortes J (2008a) Homoharringtonine for the treatment of chronic myelogenous leukemia. Expert Opin Pharmacother 9: $1029-1037$

Quintás-Cardama A, Cortes J (2008b) Therapeutic options against BCR-ABL1 T315I-positive chronic myelogenous leukemia. Clin Cancer Res 14: $4392-4399$

Riccardi C, Nicoletti I (2006) Analysis of apoptosis by propidium iodide staining and flow cytometry. Nat Protoc 1: 1458-1461

Roche-Lestienne C, Lai JL, Darre S, Facon T, Preudhomme C (2003) A mutation conferring resistance to imatinib at the time of diagnosis of chronic myelogenous leukemia. $N$ Engl J Med 348: 2265-2266

Roche-Lestienne C, Soenen-Cornu V, Grardel-Duflos N, Lai JL, Philippe N, Facon T, Fenaux P, Preudhomme C (2002) Several types of mutations of the $\mathrm{Abl}$ gene can be found in chronic myeloid leukemia patients resistant to STI571, and they can pre-exist to the onset of treatment. Blood 100: $1014-1018$

Shah MR, Kriedt CL, Lents NH, Hoyer MK, Jamaluddin N, Klein C, Baldassare J (2009) Direct intra-tumoral injection of zinc-acetate halts tumor growth in a xenograft model of prostate cancer. J Exp Clin Cancer Res 28: 84

Shah NP, Nicoll JM, Nagar B, Gorre ME, Paquette RL, Kuriyan J, Sawyers CL (2002) Multiple BCR-ABL kinase domain mutations confer polyclonal resistance to the tyrosine kinase inhibitor imatinib (STI571) in chronic phase and blast crisis chronic myeloid leukemia. Cancer Cell 2: 99-102 
Tanaka R, Kimura S (2008) Abl tyrosine kinase inhibitors for overriding Bcr-Abl/T315I: from the second to third generation. Expert Rev Anticancer Ther 8: $1387-1398$

Weisberg E, Catley L, Kujawa J, Atadja P, Remiszewski S, Fuerst P, Cavazza C, Anderson K, Griffin JD (2004) Histone deacetylase inhibitor NVP-LAQ824 has significant activity against myeloid leukemia cells in vitro and in vivo. Leukemia 18: $1951-1963$

Williams CR, Tabiosa R, Linehana WM, Neckersa L (2007) Intratumor injection of the Hsp90 inhibitor 17AAG decreases tumor growth and induces apoptosis in a prostate cancer xenograft model. J Urol 178: $1528-1532$

Yamamoto M, Kurosu T, Kakihana K, Mizuchi D, Miura O (2004) The two major imatinib resistance mutations E255K and T315I enhance the activity of BCR/ABL fusion kinase. Biochem Biophys Res Commun 319: $1272-1275$
Yu C, Krystal G, Varticovksi L, McKinstry R, Rahmani M, Dent P, Grant S (2002) Pharmacologic mitogen-activated protein/extracellular signal-regulated kinase kinase/mitogen-activated protein kinase inhibitors interact synergistically with STI571 to induce apoptosis in Bcr/Abl-expressing human leukemia cells. Cancer Res 62: 188-199

Yu C, Rahmani M, Almenara J, Subler M, Krystal G, Conrad D, Varticovski L, Dent P, Grant S (2003) Histone deacetylase inhibitors promote STI571-mediated apoptosis in STI571-sensitive and -resistant Bcr/Abl+ human myeloid leukemia cells. Cancer Res 63: 2118-2126

Zisterer DM, Campiani G, Nacci V, Williams DC (2000) Pyrrolo-1, 5-benzoxazepines induce apoptosis in HL-60, Jurkat, and Hut-78 cells: a new class of apoptotic agents. J Pharmacol Exp Ther 293: 48-59

Zisterer DM, McGee MM, Campiani G, Ramunno A, Fattorusso C, Nacci V, Lawler M, Williams DC (2001) Pyrrolo-1,5-benzoxazepines: a new class of apoptotic agents. Biochem Soc Trans 29: 704-706 